\title{
APPLICATION OF EYE-TRACKING IN DRIVERS TESTING: A REVIEW OF RESEARCH
}

\section{BRONISŁAW KAPITANIAK, MARTA WALCZAK, MARCIN KOSOBUDZKI, ZBIGNIEW JÓŹWIAK, and ALICJA BORTKIEWICZ}

Nofer Institute of Occupational Medicine, Łódź, Poland

Department of Work Physiology and Ergonomics

\begin{abstract}
Recording and analyzing eye movements provide important elements for understanding the nature of the task of driving a vehicle. This article reviews the literature on eye movement strategies employed by drivers of vehicles (vehicle control, evaluation of the situation by analyzing essential visual elements, navigation). Special focus was placed on the phenomenon of conspicuity, the probability of perceiving an object in the visual field and the factors that determine it. The article reports the methods of oculographic examination, with special emphasis on the non-invasive technique using corneal reflections, and the criteria for optimal selection of the test apparatus for drivers in experimental conditions (on a driving simulator) and in real conditions. Particular attention was also paid to the helmet - or glass-type devices provided with 1 or 2 high definition (HD) camcorders recording the field of vision and the direction of gaze, and the non-contact devices comprising 2 or 3 cameras and an infrared source to record eye and head movements, pupil diameter, eye convergence distance, duration and frequency of eyelid blinking. A review of the studies conducted using driver eye-tracking procedure was presented. The results, in addition to their cognitive value, can be used with success to optimize the strategy of drivers training.
\end{abstract}

Key words:

Eye-tracking, Visual strategy, Drivers, Visual fatigue, Road accidents

\section{HISTORICAL BACKGROUND}

The interest in eye movement is not new. As early as in the 11th century, Ibn al Haytam described, for the 1st time, fast eye movements that occurred when tracking moving objects. However, it was not until the 18th century that the studies on the nature of these movements were undertaken. The 1st description of these movements was presented by Porterfield (1737) and then, later in 1792 [1], Wells described fast movements of eyes, which he called nystagmus. In the 19 century, Purkynjě's studies on the mechanisms of perception of brightness were a major contribution [1]. In 1879, Javal invented an ophthalmoscope used to examine eye movements, by the use of which he described the 1st saccades and fixations. A comprehensive historical overview of research on eye movements was presented by Wade in 2010 [1].

The 1st invasive registration of eye movements using contact lenses (1897) is attributed to 2 scientists - Huey and Delabarre [1]. The 1st non-invasive recordings, made in the early 20th century, using optical instruments were performed by many researchers, among them: Dodge, Erdmann, and Cline [1]. Since 1905, film cameras have been

This work was prepared partly in the frame of project entitled: "Integrated system for monitoring the psychical and physical condition of road vehicle drivers to minimise hazards in road traffic" financed by Innovative Economy Programme: Priority 1. Research and Development of Modern Technologies Activity (UDA-POIG.01.03.01-10-085/09). Project manager: Prof. Alicja Bortkiewicz.

Received: May 6, 2014. Accepted: March 26, 2015.

Corresponding author: A. Bortkiewicz, Nofer Institute of Occupational Medicine, Department of Work Physiology and Ergonomics, św. Teresy 8, 91-348 Łódź, Poland (e-mail: alab@imp.lodz.pl). 
used for that purpose notably by Judd, MacAllister, Buswell, and Steel. In 1921, Gilliland performed a 2-dimensional recording of eye movements [2].

Research on visual reading strategy started in the 1930s [1]. In 1931, Earl and Taylor developed 2 devices, called "Ophthalmograph" and "Metronoscope," that enable accurate recording of eye movements, and above all, of saccades and fixations [1].

The 1st "eye-tracker" (a device for recording eye movements) in a form of a helmet equipped with a mini-camera was the work of Hartridge and Thompson (1948) [3]. It was improved by Shackel in 1960 [4], and then in 1962 by Mackworth and Thomas [5]. In 1967, Yarbus [1] started the research using his oculometer, and thus, opened a wide, new field of research. The era of modern eyetracking began in the 1970s with the studies performed by Young and Sheena and their successors [6].

The use of eye-tracking to control visibility of the elements of visual advertising was the work of an advertising agency Euro RSCG and it started in the late 1970s. Followers of these applications included other public agencies and, later on, website creators. This technique made it possible to optimize and minimize their advertising messages while ensuring their better advertising effect.

Application of this technique to observe driving strategies also dates back to the 1970s. Already in 1971, Soliday published a survey of reports on the studies of drivers [7]. One of the 1st devices used in these studies was the Japanese NAC Eye Marker Recorder. At that time, studies on the differences in visual strategies of the experienced and novice drivers started and concept of "conspicuity" was coined, denoting the ability to perceive an element, associated with a concept of the functional field of vision [8-10]. In 1972 Mourant and Rockwell [11] found different visual patterns in the novice and experienced drivers with the TV eye-movement system.

In the 1980s and 1990s, extensive research on eye movements took place, mainly related to the development of information technology and miniaturization of optical equipment. A comprehensive review of the literature in that area was published in 1998 by Rayner who analyzed over 900 publications [12]. It focused on the studies of eye movements during reading and other information processing tasks, such as music note reading, writing, or observing a scene. The main focus of the review was on reading as a specific example of cognitive processing.

The main issues in relation to reading are: characteristics of eye movements, integration of information through the analysis of saccades, eye movement control and individual differences. The author summarizes the review by claiming that the analysis of eye movements has proved to be extremely valuable in the study of the processes of perception and information processing. Unfortunately, the results cannot be generalized to various forms of cognitive tasks, but characteristics of eye movements in a variety of tasks are necessary to understand cognitive strategies.

In our paper we will try to present the actual status of research, in particular concerning the visual strategy studies on driving. This presentation is not exhaustive, but it can be useful for the future perspectives of research.

\section{TYPES OF EYE MOVEMENTS}

During a visual task, basic eye movements include saccades - rapid eye movements at a speed of up to $500^{\circ}$ per s or even $800^{\circ}$ per s. The amplitude does not exceed $8^{\circ}$ and the duration is $20-200 \mathrm{~ms}$, depending on the amplitude. The latency - the time from the moment a target appears in the visual field to the start of eye movement - ranges from 100-300 ms. It depends primarily on the quality of cognitive process, increasing with its complexity. Latency is also increased when the functional field of view extends to the peripheral zone, or when a high precision is required in a target location.

The sensitivity of visual perception is much reduced during saccades; the phenomenon is called "saccadic suppression" 
and it is the subject of a serious debate. Its effect is not conscious, most likely due to the existence of the inhibiting mechanism in the central nervous system [13].

Many studies cited by Rayner suggest that some cognitive functions are inhibited during saccades, at least for simple tasks [12]. However, a person does not realize the gaps in mental activity during eye movements because the saccade duration is very short. Studies have shown that the processes of lexical analysis while reading are not inhibited during saccades [14].

Saccades should be distinguished from 3 other types of eye movements - pursuit, vergence, and vestibular movements (synchronizing eye movements with movements of the head).

Pursuit occurs when our eyes follow a moving target; the speed of those eye movements is much slower than the saccade - below 30/s. If a target is moving quickly across the entire field of vision, pursuit is often accompanied by a saccade to catch up with the target. Some authors claim that it is desirable to analyze slow eye movements to evaluate the state of a driver's activity [15].

Vergence eye movements occur when the eyes are guided to the centre of the field of view to focus on a near object. They reflect the compensation of binocular vision at varying distances. When a target of observation is located at a distance of far vision ( $>6 \mathrm{~m}$ ), eye movements are parallel. They become convergent when the target is located at a distance of near vision $(<1 \mathrm{~m})$, as they serve to position the image within the foveal area (about $2^{\circ}$ around the visual axis). These movements are also used to track an object when it is approaching or receding. Tracking an object that moves in 3 dimensions - that is moves laterally and recedes at the same time - requires combined pursuit/vergence movements. Vergence movements are usually slow, rarely exceeding 10/s.

Vestibular eye movements appear to compensate for movements of the head and body, in order to maintain the same direction of a view. When the head moves, 2 types of reflex movements are observed - vestibulo-ocular movements and optokinetic nystagmus. These movements serve to stabilize an image in the foveal zone and, in contrast to the pursuit, are not consciously controlled. The vestibuloocular movements are primarily associated with movements of the head and are generated by the reaction of the vestibular system in the inner ear. They are very fast (faster than the pursuit) and precise. In contrast, optokinetic nystagmus is a reflex generated by translations of the optical system taking place in the central nervous system $[16,17]$.

Although a lot of research concerns importance of these 3 types of movements, saccade movements are considered to be the most important for the cognitive process. It also seems worthwhile to mention 3 other types of eye movements, characterised by high frequency and low amplitude: nystagmus, drifts and microsaccades. Although analysis of eye movements makes use of the concept of the fixation relative to interrupting eye movement at some point between 2 saccades, in fact the concept is misleading. Eyes are never really fixed, because physiological nystagmus is continuous and has a nature of low-amplitude $\left(<1^{\prime}\right)$ and high-frequency vibrations $(50-100 \mathrm{~Hz})$. Its role is not entirely clear, although it is often assumed that these oscillations are related to the perceptual activity of neurons in the retina. Drifts (movements with an amplitude of 2-120') and microsaccades (fast movements with an amplitude of 2-60') are movements the precise meaning of which is not known, but it is assumed that they represent the correction of inaccurate eye movement control process.

Permanent movement of images on the retina in an irregular manner constitutes the cumulative effect of these micro-movements. The amplitude of these movements is about $0.1^{\circ}$, while the distance between the receptors in the retina is about $0.01^{\circ}$, which is necessary for the perception of the images. Pharmacological blocking of these movements causes functional blindness. 
Between the 2 saccades, eyes stop on the object being viewed for about 200-600 ms, and the stops are referred to as fixations. Their duration depends mainly on the intensity of the luminance contrast, complexity of the area of vision and cognitive load. Depending on the different task of reading, fixations have different characteristics; their duration varies between $200 \mathrm{~ms}$ on silent reading to $400 \mathrm{~ms}$ on typing (Rayner) [12].

In the studies concerned with visual information processing, as well as with general visual strategy, these are precisely those characteristics that are most commonly used to quantify eye movement.

In the task of driving, the saccades could be shorter than $200 \mathrm{~ms}$ [18]. In the study concerning responses to the critical hazard events, in a driving simulator, Horrey and Wickens using the Smart Eye Pro system have observed the saccades from $60 \mathrm{~ms}$ to $200 \mathrm{~ms}$ [19]. They have also measured "glance duration" which is defined as time of watching an object. This time in their study was $0.1-3 \mathrm{~s}$. Martens and Fox [20] have performed the same measurement of glance duration in a study about recognition of traffic signs in driving a low cost simulator. Using the eyetracker ISCAN they have found durations from 0.3 to $2 \mathrm{~s}$.

\section{Oculometry}

Oculometry is a method that allows measurement of eye movements and gaze direction tracking in the visual field test. Historically, 3 types of oculometry were used: electrooculographic, galvanometric and the corneal reflection techniques.

The electrooculographic technique (EOG) involves measurement of bioelectric potential differences caused by corneal-retinal eye movements. These potentials are recorded using electrodes placed around the eyes. The received signal is filtered to eliminate artefacts. This technique is very precise in assessing the range of motion with good time resolution and poor spatial resolution. It is one of the 1st techniques used in clinical trials [21]. This technique does not allow to track the direction of gaze, since it can track eye movements only when the head is immobilized. It is not suitable for long-term recording either, due to the need of adhesive fastening of the electrodes around the eyes. However, it has been applied with success in the conditions of experimental studies using a simulator [22].

The galvanometric technique consists in measuring changes in the electromagnetic field by means of contact lenses applied onto the cornea, equipped with an induction coil. It is very precise; however, due to its invasiveness, it is very restrictive and impossible to use in the field studies.

The corneal reflection technique is currently the only technique that allows tracking direction of gaze in a noninvasive way. It involves using a source of infrared light reflected from the cornea, which can be tracked in the field of view. This is possible owing to the fact that the reflection from the moving parts of the pupil can be separated from the reflection from the static elements of the cornea, whereby it is possible to precisely determine the position of eye from the relative positions of the reflections. This particular technique is currently being used for long-term tracking of eye movements in the field studies [23,24].

\section{Eye movement recording methods}

\section{used in the field studies}

The studies of visual strategies during visual tasks are carried out mainly by means of the apparatus using the corneal reflection technique. The recent years have seen a rapid development of that technique, which enabled production of a number of devices for long-term recording in most work situations. It involves superposing the reflection of an infrared light ray sent in the direction of the cornea from a source placed adjacent to the eye, onto the image of the field of view filmed by a camera mounted on driver's head. Suitable software enables precise tracking of gaze direction.

The corneal reflection technique cannot be used in conditions of high-intensity solar radiation, which makes it 
impossible to identify the infrared ray produced by the apparatus. In this case, you can replace it with a computer program that simulates the driver's head and eyes to assay gaze direction, with a slightly lower accuracy than that of the corneal reflection method. The computer-simulation method requires a high efficiency computer system able to produce such a model in real time, and necessitates very high precision in setting the cameras. Currently it is used, among others, in the FaceLab system.

\section{The criteria used in selecting methods of registration during the field studies}

Currently in the field studies, 2 types of devices are used: devices placed on driver's head, such as a helmet or glasses, and independently installed devices without physical contact with the person to be tested. The latter are particularly valuable in the field studies, where the use of helmets and even glasses is not always possible or does not guarantee the maximum safety of the test.

Drewes has performed a study about following visual targets on screen in order to optimise eye-gaze user interface design [25]. After a deep review of current literature he has proposed criteria for optimal eye movement recording apparatus concerning eye cameras as well as scene cameras. Each criterion is important, depending on the application of the device and the range of tests to be performed using that device [25]. Here are the 5 criteria he distinguishes:

- Accuracy - the limit of accuracy of the eye is approximately $\pm 0.5^{\circ}$; most devices meet this criterion; only studies on micro-saccades and rapid eye movements require better accuracy.

- Resolution - each device records gaze direction at specified intervals. The video camera recording frequency is usually determined by the specified number of frames per second, which is not always sufficiently high for a precise observation of saccades, especially in human/computer interface studies.
- Reliability - the camera should work reliably in every situation and with every person; poor lighting conditions may, however, interfere with its operation; interferences may also occur in people who wear contact lenses or glasses.

- Low-level filter - the data recorded directly by the device are subject to artefacts related to blinking or closing the eyelids; filtering and smoothing the signal causes the destruction of information on the movements of small amplitude; the type of filter used determines the movements actually taken into account in the further analysis.

- Programming and data visualization interface - most devices have a software package for visualizing and evaluating the recorded eye movements; however, it is very important to be offered the possibility of using additional applications that make it possible to adapt the machine to the test better.

According to Ould et al., these criteria should be extended [26]. In the opinion of that author, who provides an overview of the literature on the subject, a good apparatus for "eye-tracking" study should meet the following requirements [26]:

- allow access to the field of view without distortion, with an easy access to the face and head,

- operate without any contact with the subject,

- artificially stabilize the retinal image as necessary,

- be accurate up to at least a few minutes of arc, the accuracy is limited by the combined effects of non-linearity, distortion, delay and other sources of error,

- have a resolution of $1 \mathrm{arc}$ min per s, and thus, be able to detect the slightest changes in the position of eye,

- have a wide dynamic range of movement: from $1 \mathrm{~min}$ arc to $45^{\circ}$ for the position of eye and $1-800^{\prime} / \mathrm{s}$ for the speed of eye movement,

- have a good rate of reaction (e.g., $100 \mathrm{~Hz}$ ),

- be able to give an answer in real time,

- be able to make measurements in 3 planes of eye movements (anterior-posterior, sagittal and transverse) and be insensitive to the translation of eye, 
- be easily adaptable to binocular recording,

- not interfere with the registration of other physiological functions,

- be easy to use by different subjects.

\section{Apparatus for testing the visual strategy}

There are 3 main types of apparatus for testing visual strategy: helmet devices, contactless devices and special equipment.

\section{Helmet devices}

It was the 1st device used to test visual strategies while driving. One of the first was the Nac Eye Marker, the newer versions were used to test drivers in the 1970s and 1980s [1]. Currently, the apparatus used for this type of research is extremely miniaturized to allow the use of lightweight glasses instead of a full helmet.

The apparatus characterized by high accuracy of the measurements can be designed either for use with an immobilized, or a freely movable head. They are suitable for use in a laboratory, where they can work smoothly together with apparatus for recording biological signals (electroencephalography (EEG), electromyography (EMG), magnetic resonance imaging (MRI)).

Nowadays, the apparatus used for field studies consists mostly of lightweight glasses fitted with 1 or 2 high definition (HD) digital cameras recording the field of vision and direction of gaze, and a minicomputer. The recorded data can be observed in real time.

The new family of devices combines 2 technologies - ultra high speed tracker for recording movements in 3D, and power-assisted eye-movement-controlled system for controlling movements of the recording cameras. Superposing the field of vision on the wide-angle panoramic camera image results in a hybrid image, allowing a very precise tracking of gaze direction.

\section{Contactless devices}

The contactless apparatus is much better suited for testing drivers due to the fact that the driver is completely independent of a device that could potentially limit his freedom of movement, or even visibility.

A device of this type consists of 2 or more HD cameras and an infrared source placed between the cameras. The cameras are placed in front of the face of the subject in a specific location relative to the subject's eyes. An additional camera can be set so as to record the subject's field of vision. The device simultaneously captures eye and head movements, pupil diameter, eye convergence distance and duration, and frequency of eyelid blinking. Some devices also have the ability to track gaze not only with infrared reflection from the cornea, but also by creating a computer model of the head and eyes. This ensures that the device operates effectively even under strong sunlight, which excludes the use of infrared light. Additionally, there is also the ability to analyze facial expressions based on the dynamics of movements of the mouth, eyes, eyebrows, etc.

Simpler devices are provided for testing visual strategy during observation of the screen. An HD camera placed below the screen makes it possible to record eye movements, head movements and pupil diameter. They are used primarily for analyzing tasks of reading the screen, and therefore, can be used for research in a simulator, while they are not suitable for real-time test driving. Owing to the integration of the eye-tracking system with the computer screen, the apparatus is very convenient for practical use. The only limit is your computer screen that restricts the scope of control of eye movements.

\section{Special devices}

These include equipment used in basic research. In the last decade, rapid progress in studies on neurophysiology has been possible thanks to breakthroughs in imaging techniques such as Positron Emission Tomography (PET), computed tomography, magnetic resonance imaging (MRI). Thus, test devices have been developed, adapted to track eye movements in a tunnel, or in other 
similar conditions. In order to reliably classify the areas of brain involved in the control of eye movements, it is important to accurately measure actual eye movements. For this purpose, the infrared ray is guided without contact through the optic fibre to the eye of the subject. Two additional optic fibre cables receive the light reflected by the cornea. By calibrating the eye position in the scanner, it is possible to estimate the position of an eye with high temporal and spatial resolution.

Recent years have seen considerable progress in research on the use of catadioptric cameras [27]. These cameras are made up of a system of mirrors and lenses to produce a panoramic view. They have been used for at least 10 years in robotics, in particular in the construction of self-moving robots. Recently they have been used as a driving aid. A device for recording eye movements using this type of camera is currently being developed [27].

\section{Visual strategy on driving}

During looking ahead, the field of view may be divided into 3 zones: foveal, parafoveal and peripheral. Visual acuity is excellent only in the foveal zone, which is located within $2^{\circ}$ from the central axis of vision. The acuity is much poorer in the parafoveal area (about $5^{\circ}$ from the central axis of vision), and quite weak in the peripheral zone. Hence, the tendency of eye movements intended to ensure good visual acuity in the whole field of view. Thus, saccades serve to quickly include the field of observation into the foveal zone, and fixations are necessary to recognise the desired information in the field.

The results cited by Rayner suggest that the required precision of recognition is essential for generation of saccades [12]. It has been observed that, in the parafoveal zone, the objects which are large enough are recognized without specific eye movements, which points to the existence of a process control system within the central nervous system. This process control system could be considered as a cognitive recognition of visual perception.
The field of view may, therefore, be functionally divided into 3 regions, in which [28]:

- the stimuli can be identified without eye movement,

- eye movement is necessary to identify the stimulus,

- identification requires head movement.

\section{CONSPICUITY}

Another problem is the ability to perceive objects in the visual field. Conspicuity is defined as the probability of perceiving an object in the visual field [29]. Among the authors there is no agreement on a clear definition, and many of them point to different aspects of the phenomenon. Many of them focus primarily on the characteristics of the viewed objects and the observer's attentiveness. These characteristics vary depending on whether the observed object is actively sought or unexpected [30].

In neuroscientists approach, conspicuity is considered as an attentional process, which could be performed on 2 component frameworks, one a bottom-up, fast, primitive mechanism that biases the observer towards selecting stimuli based on their visibility (saliency), and the 2nd - a slower, top-down mechanism with variable selection criteria under cognitive, voluntary control [31]. Quantitative evaluation of conspicuity is difficult, especially if it is to be objective. The most commonly used methods include the observer's verbal description and registration of eye movements.

Cole and Jenkins (1980) propose the following quantitative definition of conspicuity: an object is conspicuous if $90 \%$ of the observers have noted it within $0.25 \mathrm{~s}$, regardless of its location in the visual field [32].

Difficulties in assessing conspicuity through verbalization come mainly from differences in training and the ability level of the observer. These differences may render this type of evaluation quite unreliable.

Registration of eye movements is currently the only method that allows for an objective quantitative assessment of 
conspicuity $[33,34]$. Its use in the process of driving a car is becoming more and more widespread.

\section{VISUAL TASKS RELATED TO DRIVING A VEHICLE}

We can distinguish 3 basic visual tasks while driving:

- control of the vehicle,

- assessment of the situation by analyzing essential visual elements,

- navigation.

During navigation, a driver tends to choose a target point in the field of view, allowing him/her to anticipate direction of travel of the vehicle. This tendency can cause 2 types of conflict: emergence of a number of points that can be "target points" in the same visual task, or occurrence of a number of elements that could be important for driving, but related with a variety of other visual tasks, as pedestrian detection or visual control of navigation system [35]. The most important source of information that makes car driving possible comes from the moving elements which appear in a driver's field of vision. Observation of those elements provides information that helps to assess the situation and ensure smooth navigation. A driver does not knowingly receive all the information coming through the optic canal, but only that which is essential for his/her security. The probability to detect an object while driving (conspicuity) is very important for the assessment of driving effectiveness. Unfortunately, there is currently no objective method for quantitative assessment of that probability [36].

The results of questionnaire surveys and eye-tracking tests suggest that only about $10 \%$ of the written information present in a driver's field of vision is read by the driver [34]. The remaining information is neglected by the driver. The correct choice of information relevant to the safety of driving determines efficiency of a driver. In an experimental situation when a driver is instructed to read all traffic signs, his/her visual strategy changes compared to normal driving. In this case, reading time ranges $250-750 \mathrm{~ms}$, depending on the contents of the sign. Most authors have found that when driving in urban conditions, the number of the read signs decreases along with the intensity of traffic. Some authors propose to perform measurements of the maximum distance from which a driver can read the sign and the distance from which he/she actually begins to read it. The ratio of these 2 distances would be a good indicator for a proper location of traffic signs $[37,38]$.

The conspicuity of objects in a driver's field of view depends on 2 categories of factors associated on the one hand, with the characteristics of the sign (color, size, lighting, etc.), or the complexity of the situation in the field of view, and on the other hand, with the driving task. It seems that the most important factor determining efficiency of perception is the complexity of the situation in the field of view.

Quantitative assessment of complexity of the scene is extremely difficult, because objective methods are not available. Most authors make use of subjective criteria which, however, cannot be used for the quantitative assessment. Characteristics of the object can be more objective, because the size, colour, contrast or brightness can be measured [34].

With simple scenes, conspicuity is limited only by the visibility of an object. For complex scenes, the situation is complicated because of the importance of cognitive meaning (sense) of the objects present in the field of view. Unfortunately, it is not always possible to apply the results of research carried out in laboratory in controlled situations to the process of real driving, mainly due to the fact that this process applies to all multiple visual tasks at once, rather than to a single task. However, some of the results have been confirmed by tests in real conditions, such as deterioration of perception ability due to the presence of the billboards in the complex field of view on the national $\operatorname{road}[34]$.

Results of the studies on the visibility of an object are used to determine the contrast threshold $(\Delta \mathrm{Ls} / \mathrm{L}$ - ratio 
of the difference of the maximum luminance to minimum luminance values) depending on the size and position of an object relative to the central axis of vision, and complexity of the scene.

Complexity indicators that seem to be important in predicting detection of visible elements are based on the assessment of the number of objects observed, number of light sources, number of objects in the $10^{\circ}$ cone, and evaluation of mental workload. Since the average reading distance of an object is at about 2/3 of the distance of maximum readability, it seems logical to conduct evaluation of complexity at this particular distance.

It is extremely difficult to assess characteristics of the driving task objectively, especially in a real situation. Studies in laboratory conditions are always subject to a methodology-related error, whereby it is not possible to transfer results to real situations. However, conscious orientation of attention seems to affect object conspicuity. The searched object is 3 times as visible as the object accidentally present in the visual field [30].

\section{RELEVANT EYE-TRACKING INDICATORS FOR USE IN THE STUDY OF VISUAL STRATEGIES ON DRIVING}

Most common indicators in the assessment of visual strategies include: the number of fixations, average fixation time, and exploration areas of the functional vision field. These parameters were measured as early as in the 1970s [10], although the accuracy attainable at that time was not satisfactory. They are still in use considering that they can be optimized, primarily by statistical means.

Muttart et al. [39] employing a Mobile-Eye miniaturized contact system used those particular parameters in comparative studies of visual strategies of drivers of cars and motorcycles during a left turn or U-turn manoeuvre. They have found that motorcyclists were developing a much richer visual strategy than car drivers, as reflected by a greater number of fixations, especially on the objects that are on the road and on the pavement. Their strategy is to minimize the risks associated with other road users [39]. Fildes et al. [40] have measured, by means of a noncontact FaceLab, the same parameters, i.e., the number of fixations, average fixation time, percentage of area in the total field of view during fixation [40]. This apparatus allows a precise decomposition of the field of view, in terms of dividing this field into test areas, as in the EyeWorks software. Tests were made on a simulator and their goal was to compare the strategy of young (25-35 year old) and older (65-75 year old) drivers when driving in urban conditions and on the highway. The results indicate that older drivers assess traffic parameters more slowly (their fixation time is longer than in the young) and do it with less precision (the field of observation of an object on the road is greater in the elderly than in the young). The authors believe that the results justify continuation of that research.

Fiedler and Glöckner have measured the number of fixations on a visual target, and percentage of the number of total fixations throughout the measurement period [41]. Using the non-contact FaceLab apparatus, they have also measured the average time of fixation and distribution of long, medium and short fixations. Decomposition of the field of view into regions of interests was conducted depending on the capacity of the eye-tracking system.

In the studies of the dynamics of risk-taking in a computer game they have also measured the changes in the width of the pupil by the PERCLOS (Percent Eyelid Closure) system and the time of decision-making in terms of difference between the appearance of a stimulus and the associated response. The authors have recorded eye movements at $120 \mathrm{~Hz}$ sampling rate frequency and a precision of the location of the eye movement of about 0.45 . Fixation was identified with a precision of $30 \mathrm{px}$, and the recognition threshold was set at $50 \mathrm{~ms}$. The reaction time was measured with accuracy up to $5 \mathrm{~ms}$. The results confirm that the rate of change of these indicators can be useful 
for the evaluation of mental workload [42] although the algorithms based on a pupil diameter are not sufficiently robust if the light conditions change.

Lang and Qi have proposed an algorithm for detection of driver's fatigue, based on measurements of changes in a pupil diameter (PERCLOS), and the rate of blinking [42].

Assessment of the proportion of eye movements to head movements during a precise location of a visual target was conducted as early as in the 1970s. Zangemeister and Stark observed an offset (or desynchronisation) of 2 movements [43]. According to Doshi and Trivedi, a separate analysis of eye movement and head movement allows for a more accurate assessment of visual strategies [44].

It is generally recognized that errors of visual attention are responsible for a large proportion of traffic accidents [24]. Recording and analyzing eye movements provide important elements for understanding the nature of the task of vehicle driving. These results make it possible to optimize driver training strategy and prevent accidents. The cited authors suggest that in the simplest case of driving, a driver's visual fixation on straight stretches of the road can be described as focusing on the expansion point (target), i.e., on that section of the visual field in front of a driver where objects appear to be stationary, with rare gazes on the traffic signs and markers on the edge of the road. It is clear that a dangerous event usually causes a significant increase in the duration of fixation.

Kito et al. have found that the amplitude of eye movements is significantly broader when driving large vehicles (truck, bus) than during driving a small car [45]. Fixation positions are observed at approximately $50-60^{\circ}$ relative to the central axis of a driver's sight (i.e., $50-60^{\circ}$, both to left and right of the axis). Some of them are targeted at zone $0-20^{\circ}$ relative to that axis.

Dishart and Land suggest that experienced drivers receive visual information from 2 sources of information on the road in order to maintain the correct position on the lane during driving around a curve [46]. The more distant of those 2 sources is used as a target point to predict the curvature of the road. This source on the road is in the driver's field of view at the distance that the vehicle travels during the optimal $0.75-1 \mathrm{~s}$ and is used for anticipation, allowing the driver to predict curvature of the road. The other, less distant source, preceding the driver by about $0.5 \mathrm{~s}$ is used as a re-control (feedback) mechanism that allows the driver to fine-tune the manoeuvre. The studies have shown that this mechanism is present in most people, regardless of experience in driving, but its accuracy is better in experienced drivers. This mechanism occurs in most management tasks, such as driving a bicycle, horse riding or simulated driving on a computer $[47,48]$.

However, Kandil et al. [49,50] point out to a discrepancy between the results of research conducted on simulators and real-time driving. The results compared with the literature suggests that the strategy of the real driving is most often a "target point" (described above and in the Dishart's study), while during simulated driving, a target sampling strategy is more frequently observed, which involves progressively moving virtual point according to the movement of the vehicle $[49,50]$.

The main problem in conducting research on visual strategy is to identify and monitor the requirements of drivers as independent variables [51]. Potential confounding factors include the increased visual requirements, such as the increase in visual complexity, and increase in cognitive demands, such as increased processing requirements of a particular stimulus because of its importance in the situation. It seems that the overall increase in the requirements and complexity of the task tends to reduce the average duration of fixation and increases the number and frequency of fixations.

According to Duchowski, older people are less accurate in capturing scenes viewed while driving [52]. During night 
driving, the difference is even greater. During daytime driving, visual distractions, such as billboards located on the roadside of a highway, increase the frequency of errors, which is not the case at night. There is a strong correlation between the number of fixations and the response time. Older people need more fixation than younger ones to follow the same scene, as well as more fixation is necessary to recognize the scene in the circuimstances of poor visibility (fog, rain, etc.). Similar results have been obtained by Fieldes et al., who have found that older people respond more slowly than younger people, but also their visual strategy is qualitatively different and can be judged as less effective [40].

The results of experiments in which gaze is monitored in simulated driving conditions indicate that the proper task visibility depends mainly on the habits acquired by the driver during driving. The findings suggest that the standards of fixation and visual control in individuals with normal visual skills are acquired by learning [53].

The studies investigating effects of mental activity while driving suggest the desirability of an awareness campaign about the risks of concentrating on their own thoughts unrelated to the process of driving [54]. Numerous studies on the effects of performing dualtask procedure, involving driving a vehicle and talking on a mobile phone, on the efficiency of performing the main (driving) task indicate that this efficiency drops very seriously, which is reflected in the increased number of violent braking episodes, lack of control, neglecting rear mirror view and impaired strategies for recognizing objects on the road [55].

The study of Balk et al. [56] realised on a low fidelity driving simulator has shown that the percentage of fixations on the vehicles involved in hazardous events throughout the test was greater for the driving-only condition than driving and talking on a mobile (40\% vs. 29\%). The mean time spent looking at the hazardous vehicles was greater for the driving-only condition (9574.5 ms vs. $6523.4 \mathrm{~ms}$ ). The people talking on a mobile had fewer fixations on the hazardous vehicles while the hazardous event occurred (118 ms vs. $186 \mathrm{~ms}$ ). The total time spent fixating on the hazardous vehicles during the event was longer for the people in the driving-only condition (mean $(\mathrm{M})=4755.3 \mathrm{~ms}$ ) than for those talking on a mobile $(\mathrm{M}=3514.8 \mathrm{~ms})$.

Many authors have applied the analysis of eye movements to assess the level of driver's fatigue. Merat and Jamson have found differences in the level of fatigue by analyzing the pupil diameter using PERCLOS [57]. Schleicher et al. determines the level of fatigue based on the frequency of blinking and saccade characteristics [58].

\section{CONCLUSIONS}

The present review of literature indicates that the method of tracking eye movements is currently the method of choice for the study of cognitive strategies, in particular visual strategy. Currently available techniques allow the use of non-contact methods in the conditions of field test, both during simulated driving and in real traffic conditions. The results enable a quantitative assessment of objective parameters of the strategy and comparing these strategies under different experimental conditions.

Although the number of publications on the analysis of eye movements while driving increases, it appears that much of the research in this area is not published due to their direct use in concept vehicles.

It is advisable that the prospective development of that research includes, in particular, basic research intended to explain learning mechanisms that are necessary for understanding the functioning of the human cognitive system. This perspective is particularly attractive for the future of ergonomics, as it would provide a neurophysiological basis for a better understanding of the cognitive processes necessary for the proper design of the interface for information exchange between a man and the machine operated by him. 


\section{REFERENCES}

1. Wade NJ. Pioneers of eye movement research. i-Perception. 2010;1:33-68, http://dx.doi.org/10.1068/i0389.

2. Gilliland AR. Photographic methods for studying reading. Vis Educ. 1921;2:21-6.

3. Hartridge $\mathrm{H}$, Thompson LC. Methods of investigating eye movements. Br J Ophthalm. 1948;32:581-91, http://dx.doi. org/10.1136/bjo.32.9.581.

4. Shackel B. Note on mobile eye viewpoint recording. J Opt Soc Am. 1960;59:763-8, http://dx.doi.org/10.1364/ JOSA.50.000763.

5. Mackworth NH, Thomas EL. Head-mounted eye-marker camera. J Opt Soc Am. 1962;52:713-6, http://dx.doi. org/10.1364/JOSA.52.000713.

6. Young LR, Sheena D. Survey of eye movement recording methods. Behav Res Methods Instrum. 1975;7(5):397-429, http://dx.doi.org/10.3758/BF03201553.

7. Soliday M. Driver's eye movements: A literature review. Appendix D. In: Johns TR, Allen JA. Driver license and testing. Highway Safety Research Center, University of North Carolina, North Carolina; 1971. p. 15-23.

8. Cohen AS, Studach H. Eye movements while driving cars around curves. Percept Mot Skills. 1977;44:683-9, http:// dx.doi.org/10.2466/pms.1977.44.3.683.

9. Shinar D, Mcdowell ED, Rockwell TH. Eye movements in curve negotiation. Hum Factors. 1977;19:63-71.

10. Neboit M. [Simulation and learning driving]. Le Travail Humain. 1978;41(2):239-49. French.

11. Mourant RR, Rockwell TH. Strategies of visual search by novice and experienced drivers. Hum Factors. 1972;14(4):325-35.

12. Rayner K. [Eye movements in reading and information processing: 20 years of research]. Psychol Bull. 1998;124(3):372422, http://dx.doi.org/10.1037/0033-2909.124.3.372. French.

13. Ross J, Burr DC, Morrone MC. Suppression of the magnocellular pathways during saccades. Behav Brain Res. 1996; 80:1-8, http://dx.doi.org/10.1016/0166-4328(96)00012-5.

14. Rayner K. Eye movements in reading and attention in reading, scene perception, and visual search.
Q J Exp Psychol. 2009;62(8):1457-506, http://dx.doi.org/ 10.1080/17470210902816461.

15. Shin D, Sakai H, Uchiyama Y. Slow eye movement detection can prevent sleep-related accidents effectively in a simulated driving task. J Sleep Res. 2011;20(3):416-24, http://dx. doi.org/10.1111/j.1365-2869.2010.00891.x.

16. Levy-Schoen A. [Eye movements exploration]. L'année Psychologique. 1967;67(2):569-99, http://dx.doi.org/10.3406/ psy.1967.27583. French.

17. Miura T. Coping with situational demands: A study of eye movements and peripheral vision performance. In: Gale AG, Freeman MH, Haslegrave CM, Smith P, Taylor SP, editors. Vision in vehicles. Amsterdam: Elsevier, North Holland Press; 1986. p. 205-16.

18. Salvucci DD, Goldberg JH. Identifying fixations and saccades in eye-tracking protocols. Proceedings of the Eye Tracking Research and Applications Symposium. New York: ACM Press; 2000. p. 71-8.

19. Horrey WJ, Wickens CD. In-vehicle glance duration distributions, tails, and model of crash risk. Transportation research record, 2018. Washington (DC): Transportation Research Board of the National Academies; 2007. p. 22-8.

20. Martens MH, Fox MRJ. Do familiarity and expectations change perception? Transp Res Part F Traffic Psychol Behav. 2007;10:476-92, http://dx.doi.org/10.1016/j.trf. 2007.05.003.

21. Kaczmarek R. [Eye command to aid communication and environmental control for the disabled people]. Motricité Cérébrale. 1992;13:24-30. French.

22. Galley N. The evaluation of the electrooculogram as a psychophysiological measuring instrument in the driver study of driver behaviour. Ergonomics. 1993;36(9):1063-70, http:// dx.doi.org/10.1080/00140139308967978.

23. Richardson DC, Michael J, Spivey MJ. Eye-tracking: Characteristics and methods, research areas and applications. In: Wnek G, Bowlin G, editors. Encyclopedia of biomaterials and biomedical engineering. London: Taylor \& Francis; 2004. p. 1-70. 
24. Chapman PR, Underwood G. Visual search of dynamic scenes: Event types and the role of experience in viewing driving situations. In: Underwood G, editor. Eye guidance in reading and scene perception. Oxford: Elsevier; 1989. p. 369-94.

25. Drewes H. Eye gaze tracking for human computer interaction [dissertation]. München: LFE Medien-Informatik der Ludwig-Maximilians-Universität; 2010.

26. Ould AM, Perreira Da Silva M, Courboulay V. [A history of eye gaze tracking. CCSD CNRS, 2008; HAL-00215967] [cited 2014 Apr 30]. Available from: http://ccsd.cnrs.fr. French.

27. Layerle JF, Savatier X, Ertaud JY, Mouaddib EM. [Design of a catadioptric sensor for an optimal observation of the driver and the road scene]. ORASIS'09 - Congrès des jeunes chercheurs en vision par ordinateur; 2009 Jun 8-12; Trégastel, France. HAL/INRIA; 2009. French.

28. Sanders AF. Processing information in the functional visual field. In: d'Ydewalle G, van Rensbergen J, editors. Perception and cognition: Advances in eye movement research. Amsterdam: North Holland; 1993. p. 3-22.

29. Boersema T, Harm JG, Zwaga HJG. The influence of advertisements on the conspicuity of routing information. Appl Ergon. 1985;16(4):267-73, http://dx.doi.org/10.1016/00036870(85)90090-0.

30. Brémond R. The conspicuity of traffic signs in complex backgrounds. Rapport CIE. 2003;137.

31. Itti L, Koch C. A saliency-based search mechanism for overt and covert shifts of visual attention. Vision Res. 2000;40:1489-506, http://dx.doi.org/10.1016/S00426989(99)00163-7.

32. Cole BL, Jenkins SE. The effect of variability of background elements on the conspicuity of objects. Vision Res. 1984;24:261-70, http://dx.doi.org/10.1016/0042-6989 (84)90129-9.

33. Einhäuser W, Schumann F, Vockeroth J, Bartl K, Cerf M, Harel J, et al. Distinct roles for eye and head movements in selecting salient image parts during natural exploration, basic and clinical aspects of vertigo and dizziness: Ann N Y Acad Sci. 2009;1164:188-93, http://dx.doi.org/10.1111/ j.1749-6632.2008.03714.X.

34. Pottier A, Neboit M. [The ergonomic work analysis by the study of visual exploration]. Toulouse Ed Octares; 1995. p. 1-162. French.

35. Trivedi MM, Gandhi T, McCall J. Looking-in and lookingout of a vehicle: Computer-vision-based enhanced vehicle safety. IEEE Intell Transp Syst. 2007;8(1):108-20, http:// dx.doi.org/10.1109/TITS.2006.889442.

36. Van Loon EM, Khashawi F, Underwood G. Visual strategies used for time-to-arrival judgments in driving. Perception. 2010;39(9):1216-29, http://dx.doi.org/10.1068/p6067.

37. Viviani P. Eye movements in visual search: Cognitive, perceptual and motor aspects. In: Kowler EE, editor. Eye movements and their role in visual and cognitive processes. Amsterdam: Elsevier Science; 1990. p. 353-93.

38. Edquist J, Horberry T, Hosking S, Johnston I. Effects of advertising billboards during simulated driving. Appl Ergon. 2011;42(4):619-26, http://dx.doi.org/10.1016/j.apergo. 2010.08.013.

39. Muttart JW, Peck LR, Guderian S, Bartlett W, Ton LP, Kauderer C, et al. Glancing and stopping behavior of motorcyclists and car drivers at intersections. Transp Res Rec. 2011;2265:81-8, http://dx.doi.org/10.3141/2265-09.

40. Fildes B, Charlton J, Muir C, Koppel S. Driving responses of older and younger drivers in a driving simulator. Annu Proc Assoc Adv Automot Med. 2007;51:559-72.

41. Fiedler S, Glöckner A. The dynamics of decision making in risky choice: An eye-tracking analysis. Front Psychol. 2012;3:335, http://dx.doi.org/10.3389/fpsyg.2012.00335.

42. Lang L, Qi H. The study of driver fatigue monitor algorithm combined PERCLOS and AECS. International Conference on Computer Science and Software Engineering; 2008 Dec 12-14; Washington (DC), USA. Los Alamitos (CA), Washington, Tokyo: Conference Publishing Service, IEEE Computer Society; 2008, http://dx.doi.org/10. 1109/csse.2008.771. 
43. Zangemeister WH, Stark L. Gaze latency: Variable interactions of head and eye latency. Exp Neurol. 1982;75(2):389406, http://dx.doi.org/10.1016/0014-4886(82)90169-8.

44. Doshi A, Trivedi MM. Head and eye gaze dynamics during visual attention shifts in complex environments. J Vis. 2012;12(2):9.

45. Kito T, Haraguchi M, Funatso H, Sato T, Kondo M. Measurements of gaze movements while driving. Percept Mot Skills. 1989;68(1):19-25, http://dx.doi.org/10.2466/pms. 1989.68.1.19.

46. Dishart DC, Land MF. The development of the eye movement strategies of learner drivers. In: Underwood G, editor. Eye guidance in reading and scene perception. Oxford: Elsevier; 1998. p. 419-30, http://dx.doi.org/10.1016/B978-008043361-5/50020-1.

47. Land MF. Predictable eye-head coordination during driving. Nature. 1992;359(6393):318-20.

48. Lehtonen E, Lappi O, Kotkanen H, Summala H. Lookahead fixations in curve driving. Ergonomics. 2013;56(1): 34-44, http://dx.doi.org/10.1080/00140139.2012.739205.

49. Kandil FI, Rotter A, Lappe M. Driving is smoother and more stable when using the tangent point. J Vis. 2009;9(1):1-11.

50. Kandil FI, Rotter A, Lappe M. Car drivers attend to different gaze targets when negotiating closed vs. open bends. J Vis. 2010;10(4):24.1-11, http://dx.doi.org/10.1167/10.4.24.

51. Crundall DE, Underwood G, Chapman PR. How much do novice drivers see? The effects of demand on visual search strategies in novice and experienced drivers. In: Underwood $\mathrm{G}$, editor. Eye guidance in reading and scene perception. Oxford: Elsevier; 1998. p. 395-418, http://dx.doi. org/10.1016/B978-008043361-5/50019-5.

52. Duchowski AT. A breadth-first survey of eye tracking applications. Behav Res Methods Instrum Comput. 2002;34 (4):455-70, http://dx.doi.org/10.3758/BF03195475.

53. Land MF, Lee DN. Where we look when we steer. Nature. 1994;369:742-4, http://dx.doi.org/10.1038/369742a0.

54. Duchowski A, Medlin E, Cournia N, Murphy H, Gramopadhye A, Nair S, et al. 3D eye movement analysis. Behav Res Methods Instrum Comput. 2002;34(4):1-18, http://dx.doi. org/10.3758/BF03195486.

55. Muttart JW, Fisher DL, Knodler M, Pollatsek A. Driving simulator evaluation of driver performance during handsfree cell phone operation in a work zone: Driving without a clue. Washington: Transportation Research Board Annual Meetings; 2007. p. 9-14.

56. Merat N, Jamson AH. The effect of three low-cost engineering treatments on driver fatigue: A driving simulator study. Accid Anal Prev. 2013;50:8-15, http://dx.doi.org/10.1016/ j.aap.2012.09.017.

57. Balk S, Moore K, Steele J, Spearman W, Duchowski A. Mobile phone use in a driving simulation task: Differences in eye movements. J Vis. 2006;6(6):872, http://dx.doi. org/10.1167/6.6.872.

58. Schleicher R, Galley N, Briest S, Galley L. Blinks and saccades as indicators of fatigue in sleepiness warnings: Looking tired? Ergonomics. 2008;51(7):982-1010, http://dx.doi. org/10.1080/00140130701817062. 